\title{
Nachrichten
}

Am 25. September 1963 feiert Prof. Dr. E. P. T R A т z (Salzburg) seinen 75. Geburtstag.

Am 12. Dezember 1963 wird Herr Minister a. D. R I c h A R D T A т z E , Mitglied der DO-G seit 1924, 75 Jahre alt.

Am 24. August 1963 verstarb kurz vor Vollendung seines 79. Lebensjahres Prof. Dr. Hans Frhr. Geyr von Schwepenburg, Eicks, Ehrenmitglied der DO-G.

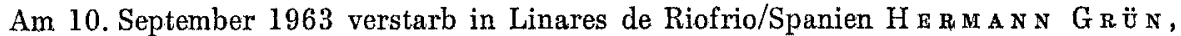
der seit 1927 in Spanien als Sammler von Wirbeltieren, besonders auch von Vögeln, tätig gewesen ist, und dessen Rat und Landeskenntnis vielen Ornithologen zugute gekommen ist.

\section{Deutsche Ornithologen-Gesellschaft}

Die 77. Jahresversammlung wird Anfang September 1964 in Hannover stattfinden.

\section{Zur Benutzung der Bücherei der DO-G}

Aus gegebener Veranlassung möchte ich alle Mitglieder, die Literatur aus den Beständen unserer Bibliothek ausleihen wollen, bitten, bei Bedarf an in Zeitschriften erschienenen Arbeiten den Titel der gewünschten Arbeit genau anzugeben, statt den ganzen Band (oft sind mehrere Jahrgänge zusammen gebunden) anzufordern. Abgesehen davon, daß dann der ganze Band für einige Zeit nicht zugänglich ist (viele Mitglieder der DO-G aus der DDR holen sich hier literarischen Rat), ist der Verlust bei Abhandenkommen der Sendung ungleich größer. Die hier vorhandenen Separatensammlungen (nämlich die der DO-G, des Zoologischen Museums, Professor Dr. Stresemanns und meine eigene) reichen für die meisten Fälle zur Befriedigung der Literaturwiunsche aus und stehen allen Mitgliedern zur Verfügung. Oftmals läßt sich der Postversand überhaupt umgehen, wenn nämlich nur wenige ganz bestimmte Angaben aus einer Arbeit erforderlich sind. In solchen Fällen lassen sich die gewünschten Daten leicht brieflich übermitteln; so ist schon vielfach verfahren worden. Wenn sich diese Möglichkeiten als undurchführbar erweisen, wird selbstverständlich der Band verschickt.

Ich bitte um Verständnis für die Bitte, ausgeliehene Literatur stets eingeschrieben zurückzusenden. Jede Unterstützung bei der pfleglichen Behandlung unserer Zeitschriftenbestände wird dankbar begrüßt werden.

G. $\mathbf{M}$.

\section{Berichtigungen}

In der Arbeit „Zur Rassengliederung von Pytilia melba (L.)“ muß es auf p. 189 von unten richtig heißen:

Ver b r e i tu ng: Süd-Angola (Jau; Clancex).

Im Beitrag „Der Grauspecht zur Brutzeit“ muß die erste Zeile auf p. 208 heißen:

"Im Ravensberger Hügelland bewohnt der Grauspecht Feldgehölze aus Eiche..."

Die Abbildungen 2 und 7 auf p. 212 und p. 220 sind um 25 bzw. ca. 30 Grad im Uhrzeigersinn zu drehen. 